\title{
Effect of Alpha Lipoic Acid on Apoptotic Mechanisms and Oxidative Stress in Pancreatic Cells of High Fat Diet Induced Type II Diabetes Mellitus in Rats
}

\author{
DOAA T. EL-SABBAGH, M.Sc.*; LAMEES M. DAWOOD, M.D.**; AHMED A. ABDALLAH, M.D.** and \\ SOBHY A. HASSAN, M.D.**
}

The Department of Medical Biochemistry, Faculty of Medicine, Kafr El-Sheikh* and Tanta** Universities, Egypt

\begin{abstract}
Background: Type 2 Diabetes Mellitus (T2DM) is a worldwide health problem with significant morbidity and mortality. $\beta$-cell failure is a main contributor to the development of T2DM. Oxidative stress and enhanced apoptosis play a critical role in pathogenesis of $\beta$-cell failure. Recently, Alpha Lipoic Acid (ALA), a universal antioxidant, has been shown to exert anti-apoptotic actions.
\end{abstract}

Aim of Study: The present study was aimed to evaluate the possible ameliorative effect of ALA against pancreatic tissue oxidative stress and apoptotic mechanisms in a rat model of High Fat Diet (HFD)-induced T2DM.

Material and Methods: Eighty albino rats were included, 20 rats received a standard diet and served as normal control group (Group I) and 60 rats were fed a homemade HFD for 6 months for induction of T2DM, only diabetics (40 rats) were included and divided into 2 groups; 20 continued to receive HFD for further 21 days, served as diabetic untreated group (Group II); 20 received ALA (50mg/kg i.p) for 21 days and served as ALA-treated group (Group III). Thioredoxin Interacting Protein (TXNIP) and cyclic Adenosine Monophosphate (cAMP) were immunoassayed in addition to determination of levels of plasma fructosamine, fasting blood glucose (FBG) and pancreatic tissue Malondialdehyde (MDA) along with pancreatic catalase and Superoxide Dismutase (SOD) activities.

Results: ALA treatment showed significant improvement in fructosamine and FBG levels, decreased MDA level and increased catalase and SOD activities, in addition to increased cAMP level and decreased TXNIP level.

Conclusion: We concluded that ALA has the ability to interfere with $\beta$-cell dysfunction associated with HFD-induced T2DM possibly by improving redox status, rescuing cAMP signaling and decreasing the level of TXNIP.

Correspondence to: Dr. Doaa T. El-Sabbagh, The Department of Medical Biochemistry, Faculty of Medicine, Kafr El-Sheikh University, Egypt
Key Words: Alpha Lipoic Acid (ALA) - High Fat Diet (HFD) - Malondialdehyde (MDA) - Thioredoxin Interacting Protein (TXNIP) - Cyclic Adenosine Monophosphate (cAMP).

\section{Introduction}

TYPE 2 Diabetes Mellitus (T2DM) is a major health problem which is attaining an epidemic stature all over the world and the scenario in developing countries is getting worse day by day. Although genetic predisposition determines in part whether individual is susceptible to T2DM or not, obesity, which results from sedentary lifestyle and unhealthy diets, is the major driver of the current global epidemic [1].

Obesity is associated with impaired insulin action in various tissues, such as muscle, liver, and adipose which implicates a secretory burden on pancreatic $\beta$-cells. Overtime, failure of $\beta$-cells to fully compensate for the increased insulin demand by insulin hypersecretion ends with the development of severe hyperglycemia and T2DM [2].

Experimental animal models based on chemical destruction of $\beta$-cells or monogenic disorders are clinically irrelevant to human diabetes. In contrast, the high-fat diet fed rodent model is more parallel to the natural pathophysiology of the disease, therefore, it has been used in several studies to induce insulin resistance with overt T2DM [3,4].

Glucolipotoxicity associated with chronic overnutrition leads to overproduction of Reactive Oxygen Species (ROS) in several body tissues including pancreatic $\beta$-cells. $\beta$-cell dysfunction is believed to be in part a consequence of the oxidative stress that occurs in this prediabetic milieu [5]. 
ROS attack various classes of biomolecules including proteins, DNA and lipids such as membrane Polyunsaturated Fatty Acids (PUFAs). The reaction of ROS with lipids is known as lipid peroxidation. The PUFA arachidonic acid is peroxidized to finally form many products one of them is Malondialdehyde (MDA) a widely accepted biomarker for oxidative stress [6]

Many studies have proved that $\beta$-cell loss due to increased apoptosis contributes largely to $\beta$-cell failure in T2DM which is induced by many mechanisms including oxidative stress, endoplasmic reticulum stress, and amyloid deposition [7].

Cyclic Adenosine Monophosphate (cAMP) is a ubiquitous second messenger that regulates many cellular processes. Recent studies showed that cAMP increases in pancreatic $\beta$-cells protect against apoptosis [8].

Thioredoxin Interacting Protein (TXNIP) is an endogenous inhibitor of thioredoxin (TRX) and is upregulated during cellular stress [9]. Hyperglycemia, among other factors, has been found to strongly induce TXNIP expression in pancreatic $\beta$-cells [10] which induces $\beta$-cells apoptosis [11].

Alpha-Lipoic Acid (ALA) is a naturally occurring short-chain fatty acid that contains a thiol bond. It acts as a powerful antioxidant and free radical scavenger [12]. Some studies have revealed that ALA exerts antiapoptotic effects [13].

Currently, there is a great need for treatment strategies that interrupt the pathogenesis of $\beta$-cells dysfunction in order to preserve a functional $\beta$. cell mass and thus preventing the development and progression of T2DM. Therefore, this study was carried out to assess the possible modulatory effect of ALA on apoptotic mechanisms as well as oxidative stress parameters of pancreatic tissue in a model of HFD-induced T2DM.

\section{Material and Methods}

Care of the animals as well as the experimental procedures was performed in Medical Biochemistry Department, Faculty of Medicine, Tanta University, Egypt, over the period from June 2017 to January 2018, in accordance with guidelines of the Ethical Committee of Faculty of Medicine, Tanta University, Egypt (approval code 31527/05/17).

\section{Study design and animal grouping:}

Eighty male albino rats, ranged from (100-150) $\mathrm{Kg}$ body weight, were obtained from experimental animal colony of Tanta University and housed in appropriate cages with a $12 \mathrm{~h}$ dark/light cycles. Rats were acclimatized for one week before the experiment and were allowed ad-libitum for a commercial standard rodent chow and tap water (El-Nasr Chemical Company, Cairo, Egypt). Then rats were divided as follows: 20 rats continued to receive the standard diet for 6 months then, 0.25 $\mathrm{ml}$ of isotonic saline solution i.p injection each per day for 21 days and served as normal control group (Group I) and 60 rats received a house prepared high fat diet for 6 months for induction of T2DM as previously described [14]. At the end of the 6 months period, the rats were subjected to Fasting Blood Glucose (FBG) checking by glucose oxidase strips (Bionime GM300, Taiwan), only diabetic ones (FBG level $>180 \mathrm{mg} / \mathrm{dl}$ ) were included in the study (40 rats) and divided into 2 groups: Group II (diabetic group) which included 20 rats and continued to receive HFD for further 21 days and Group III (ALA-treated group) which included 20 rats that received freshly prepared $\alpha$-lipoic acid in a dose of $(50 \mathrm{mg} / \mathrm{kg})$ i.p injection once daily for 21 days [15]

\section{Induction of experimental type 2 diabetes mellitus:}

T2DM was induced in second and third groups by feeding a house prepared HFD (58\% of total $\mathrm{kcal}$ as fat) for 6 months. The composition of this diet was as described before with small modification [14]. Ingredients were mixed, formed into dough with water, rolled into pellets, wrapped with plastic wrap, and stored at $20^{\circ} \mathrm{C}$ until use to minimize oxidation. These small pellets were cooked and given to rats every day.

\section{Treatment with $\alpha$-Lipoic Acid (ALA):}

After induction of T2DM in Group III, ALA was given in a dose of $50 \mathrm{mg} / \mathrm{kg}$ body weight daily by intraperitoneal injection for 21 days. ALA was freshly prepared every day by mixing ALA powder with sterile saline and $\mathrm{NaOH}$ was added until the suspension dissolved. Then the $\mathrm{pH}$ was brought to 7.4 with $\mathrm{HCl}$ [15]. The dosage of ALA was adjusted every week according to any change in body weight to maintain similar dose per $\mathrm{kg}$ body weight of rat over the entire period of treatment.

\section{Measurement of weight gain:}

Rats of all groups were weighed at the start and at the end of the experiment. Determination of the percent rise in body weight (\% BWt gain) through the experiment was done using this formula:

$$
\text { (Final BWt-Original BWt) }
$$




\section{Blood and tissue sampling:}

At the end of the experimental period ( 6 months), all rats were fasted overnight, and then sacrificed. Blood was collected in EDTA-containing tubes followed by immediate centrifugation (average centrifugal force, about $2000 \mathrm{xg}$ ) for $20 \mathrm{~min}$ then plasma was separated from the deposits by dry clean Pasteur pipettes in Eppendorf tubes. Abdomen and thorax were opened, pancreas was dissected carefully, washed three times with ice cold saline to remove extraneous materials, weighed and blotted individually on ash-free filter paper. Each pancreatic tissue was wrapped in aluminum foil and stored at $-70^{\circ} \mathrm{C}$ till homogenized on ice with $10 \mathrm{mM}$ phosphate buffer saline ( $\mathrm{pH} 7.4)$ and the homogenate then stored at $-80^{\circ} \mathrm{C}$ till the time of analysis.

Determination of blood glucose and fructosamine levels:

Fasting Blood Glucose (FBG) and plasma fructosamine levels were measured spectrophotometrically using commercial kit (Biodiagnostic Company, Egypt).

\section{Assessment of redox status:}

Pancreatic tissue malondialdehyde level was measured spectrophoto-metrically as previously described [16] using commercial kit (biodiagnostic company, Egypt). The activities of enzymatic antioxidants catalase and superoxide dismutase were assayed in pancreatic tissue homogenate using reagent kits purchased from biodiagnostic company, Egypt, as previously described $[\mathbf{1 7 , 1 8 ]}$
Assay of cAMP and TXNIP:

TXNIP and cAMP levels in pancreatic tissue homogenate were measured using commercial Enzyme Linked Immunosorbant Assay (ELISA) kit (Sunred Biological Technology Co., Ltd, Shanghai, China) according to manufacturer's instructions. Color development was monitored by absorbance at $450 \mathrm{~nm}$ with a microplate reader (Stat Fax 2100, NY, USA).

\section{Statistical analysis:}

The data were analyzed using Statistical Package for Social Sciences (SPSS), version 16.0 for Windows (SPSS, Chicago, IL). One-way analysis of variance (ANOVA) was used followed by TUKEY test to compare various groups with each other. Results were expressed as mean $\pm \mathrm{SE}$ and values of $p>0.05$ were considered non significantly different, while those of $p<0.05$ were considered significant.

\section{Results}

Body weight, glycemic parameters and redox status:

The diabetic group of rats showed significant increase of \% BWt gain, elevated FBG and plasma fructosamine levels, and elevated MDA level while the activity of SOD and catalase was significantly decreased in diabetic group $(p<0.05)$ when compared to normal control group. Treatment with ALA showed significant improvement in these altered parameters as showed when comparing ALA-treated group with diabetic untreated group $(p<0.05)$ (Table 1).

Table (1): Comparative statistics of studied biomarkers between all of the studied groups.

\begin{tabular}{|c|c|c|c|c|c|}
\hline \multirow{2}{*}{ Parameters } & \multirow{2}{*}{$\begin{array}{c}\text { Group IA } \\
\text { (normal control group) } \\
(\mathrm{n}=20)\end{array}$} & \multirow{2}{*}{$\begin{array}{c}\text { Group IIB } \\
\text { (Diabetic group) } \\
(\mathrm{n}=20)\end{array}$} & \multirow{2}{*}{$\begin{array}{c}\text { Group IIIC } \\
\text { (ALA-treated group) } \\
(\mathrm{n}=20)\end{array}$} & \multicolumn{2}{|c|}{ ANOVA } \\
\hline & & & & $\mathrm{F}$ & $p$-value \\
\hline BWt gain \% & $52.646 \pm 902^{b^{\prime} c}$ & $221.497 \pm 10.280^{\mathrm{a}^{\prime} \mathrm{c}}$ & $80.469 \pm 16.58^{a^{a} b}$ & 1067.326 & $<0.001 *$ \\
\hline FBG (mg/dl) & $87.600 \pm 8.641^{b^{\prime} c}$ & $183.250 \pm 9.613^{\mathrm{a}^{\prime} \mathrm{c}}$ & $165.400 \pm 6.476^{\mathrm{a} b}$ & 742.537 & $<0.001 *$ \\
\hline Fructosamine $(\mathrm{mmol} / \mathrm{L})$ & $151.550 \pm 34.992^{b^{\prime} \mathrm{c}}$ & $395.550 \pm 82.819^{\mathrm{a}^{\prime} \mathrm{c}}$ & $331.450 \pm 39.352^{\mathrm{a} \cdot \mathrm{b}}$ & 99.676 & $<0.001 *$ \\
\hline MDA (mmol/mg tissue) & $0.314 \pm 0.203^{b^{\prime} c}$ & $0.854 \pm 0.133 \mathrm{a}^{\prime} \mathrm{c}$ & $0.664 \pm 0.272^{\mathrm{a}^{\circ} \mathrm{b}}$ & 33.846 & $<0.001 *$ \\
\hline Catalase (U/gm tissue) & $86.482 \pm 17.894 b^{\prime} c$ & $50.054 \pm 12.473 \mathrm{a}^{\prime} \mathrm{c}$ & $68.917 \pm 25.399^{a}{ }^{\circ} b$ & 17.765 & $<0.001 *$ \\
\hline SOD (U/gm tissue) & $27.042 \pm 2.061 \mathrm{~b}^{\prime} \mathrm{c}$ & $18.621 \pm 2.914^{\mathrm{a}^{\prime} \mathrm{c}}$ & $20.760 \pm 2.149^{a^{a} b}$ & 66.234 & $<0.001 *$ \\
\hline TXNIP (ng/mg tissue) & $1.311 \pm 0.772 b$ & $2.129 \pm 0.600^{\mathrm{a}^{\prime} \mathrm{c}}$ & $1.505 \pm 0.610 \mathrm{~b}$ & 8.260 & $<0.001 *$ \\
\hline \multicolumn{6}{|c|}{$\begin{array}{l}\text { Data are mean } \pm \text { SD of a group of } 10 \text { rats. } \\
\text { Statistical analysis was carried out using one-way analysis of variance (ANOVA) with Tukey's post-hoc test. }\end{array}$} \\
\hline $\begin{array}{ll}\text { FBG } & \text { : Fasting Blood } \\
\text { MDA } & : \text { Malondialdeh } \\
\text { SOD } & : \text { Superoxide D } \\
\text { cAMP } & : \text { Cyclic Adeno } \\
\text { TXNIP } & : \text { Thioredoxine }\end{array}$ & $\begin{array}{l}\text { llucose. } \\
\text { le. } \\
\text { mutase. } \\
\text { ne Monophosphate. } \\
\text { teracting Protein. }\end{array}$ & $\begin{array}{l}\text { Superscript }{ }^{a, b, c} \text { rep } \\
\text { a : Significance from } \\
\mathrm{b}: \text { Significance from } \\
\mathrm{c}: \text { Significance from } \\
*: p<0.05 \text { is signific }\end{array}$ & $\begin{array}{l}\text { resent significant differen } \\
\text { Group I. } \\
\text { Group II. } \\
\text { Group III. } \\
\text { cant. }\end{array}$ & ice between & groups: \\
\hline
\end{tabular}


cAMP and TXNIP in pancreatic tissue:

The diabetic group showed significantly increased TXNIP level and significantly decreased cAMP level when compared to normal control group. However, ALA-treated group showed an opposite pattern, TXNIP was significantly decreased while cAMP was significantly increased as compared to diabetic untreated group $(p<0.05)$ (Table 1).

\section{Correlations matrix of the studied parameters:}

All correlations are summarized in (Table 2). In diabetic group, \% BWt gain was significantly positively correlated to FBG and fructosamine levels. In addition tissue MDA level was significantly positively correlated to tissue catalase and SOD enzyme activity. However, tissue SOD enzyme activity was significantly negatively correlated with tissue TXNIP level.

Table (2): Correlation matrix for the studied parameters in Group II (diabetic group).

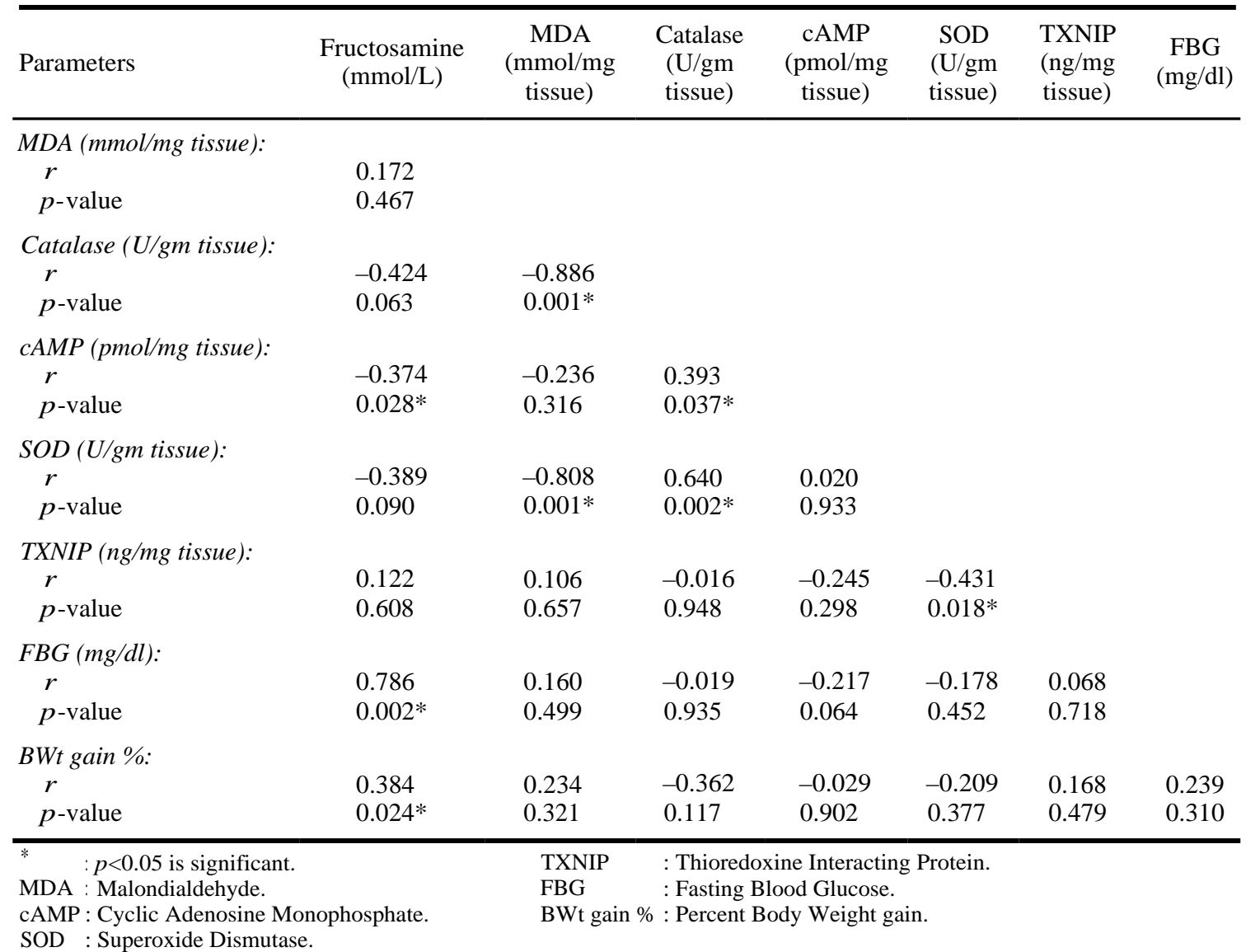

\section{Discussion}

Feeding a HFD has been widely used for inducing T2DM in the experimental animals by a mechanism that involves induction of obesity-associated insulin resistance with overt T2DM [19] . Obesity is associated with excessive ROS generation as a result of several mechanisms including glucolipotoxicity, mitochondrial dysfunction, and systemic low grade inflammation which causes oxidative stress that culminates in $\mathrm{P}$-cell dysfunction through the induction of apoptosis and suppression of insulin biosynthesis [20]. In addition, chronic exposure to saturated FFAs, among other factors, contributes to P-cell apoptosis (lipotoxicity) [21].
Recently, research studies are directed towards providing strategies for interrupting the pathophysiological processes underlying $\mathrm{P}$-cell failure in order to preserve a functional $\mathrm{P}$-cell mass thus preventing the development or progression of T2DM.

The current study was planned to evaluate the effect of ALA, a powerful antioxidant recently proved to protect against apoptosis [13], on apoptotic mechanisms and oxidative stress parameters of pancreatic tissues in a model of HFD induced T2DM. In accordance with previous research [22], the present study revealed that the rat model of T2DM was successfully established by feeding a 
HFD over 6 months, at which time, the body weight was greatly increased as compared to a standard diet fed control rats.

The development of T2DM was confirmed by the significantly elevated levels of FBG and plasma fructosamine in diabetic group as compared to the normal control group. The observed increased levels of fructosamine in diabetic group is due to the presence of excessive amounts of blood glucose. During diabetes the excess of glucose present in blood reacts with proteins mainly albumin to form fructosamine [23]. Estimation of fructosamine level has been found to be particularly useful in monitoring the effectiveness of therapy in diabetes [24] In the present study, intraperitoneal injection of ALA significantly decreased the $\%$ body weight gain in addition to the levels of FBG and fructosamine in ALA-treated group as compared to diabetic group. These results indicated the effectiveness of ALA in lowering body weight and improving glycemic control thus preventing the pathogenesis of diabetic complications caused by impaired glucose metabolism in obese individuals with T2DM. The results herein were in harmony with previous reports where ALA was found to be effective in reducing body weight [25]. Another study reported a decrease in levels of fructosamine $\&$ blood glucose upon ALA treatment in Alloxan induced diabetes in rats [26].

In this study, to assess the oxidative state of pancreatic tissue associated with HFD induced T2DM, we measured the tissue level of MDA, a by-product of lipid peroxidation frequently used as oxidative stress marker [27]. Results revealed a significantly increased MDA level in diabetic group when compared to control group which indicates that oxidative stress may be implicated in mechanisms by which HFD induces T2DM. A previous study reported increased MDA level in brain tissue of rats fed high fat diets [28]. Elevated plasma free fatty acids \& hyperglycemia which associate with feeding high fat diet contributes to oxidative stress via enhancing mitochondrial generation of superoxide anions [20]. On the other hand, upon ALA treatment MDA level was significantly decreased as compared to diabetic group. As previously reported [29], ALA treatment increased MDA level in renal tissue homogenate of Goto-Kakisaki (GK) diabetic rats, the author explained this improvement by ALA ability to regenerate other antioxidants such as Vitamin C, A \& Superoxide Dismutase (SOD) whose level was also improved in ALA treated group.
SOD and catalase are two main enzymes of the antioxidant defense system in our body. While SOD acts by the dismutation of superoxide anion into hydrogen peroxide, catalase acts to safely decompose hydrogen peroxide into oxygen and water [30]. In the current study, in an attempt to assess the antioxidant effect of ALA against HFD induced T2DM, we measured the activity of catalase \& SOD in pancreatic tissue. Results revealed a statistically significant decreased activity of both catalase \& SOD in diabetic group compared to control group. This can be explained by the increased oxidative stress associated with obesity \& T2DM resulting from exaggerated free radicals generations. Exaggerated free radicals may cause depletion of the anti-oxidant enzymes level in addition may cause oxidation of their protein structure that may be the reason for the decreased enzyme activity. In agreement, previous studies reported decreased SOD \& catalase activities in pancreatic tissue of STZ-induced type 2 diabetic rats [31]. Meanwhile, upon ALA treatment, the treated group showed a statistically significant increased SOD \& catalase activities as compared to the untreated diabetic group. Which confirms the antioxidant function of ALA \& its ability to scavenge deleterious \& toxic ROS retrieving antioxidant enzymes activity \& improving redox state. Of relevance, a recent study reported that pretreatment with ALA reduced MDA concentration $\&$ increased the activities of catalase, SOD, and glutathione peroxidase in pesticide exposed rats [32].

cAMP is a second messenger produced by adenylyl cyclase enzymes in response to several stimuli and it regulates many cellular processes. Two major downstream effectors of cAMP are Protein Kinase A (PKA) \& exchange protein directly activated by cAMP (Epac $1 \&$ 2) [33]. Previous studies revealed that GLP-1 inhibits P-cell apoptosis and enhances 0 -cell mass \& it mediates this action via elevation of 0 -cells cAMP concentration [34]. PKA phosphorylates and activates CREB which increases the expression of antiapoptotic proteins BCL-2 and BCL-X1 [35,36]. EPAC $1 \& 2$ activates Rap1 that stimulate $\mathrm{P}$-cell proliferation most probably via interface with the mTOR complex [37]. In addition, cAMP was found to inhibit caspase activation in 0 -cells [38]

In the present study, cAMP level was estimated to evaluate its role in mediating the hypothesized anti-apoptotic role of ALA in pancreatic tissue of rats with HFD induced T2DM. Diabetic group showed significant decrease in cAMP level when compared to control groups. In harmony with this 
result Tian and Sol in 2015 reported that chronic exposure of mouse and human pancreatic islets to elevated levels of the fatty acid palmitate caused defective cAMP generation in response to glucose which consequently caused a deteriorated glucose induced-insulin secretion and demonstrated that this effect of palmitate was mediated through downregulation of certain adenylyl cyclases [39] On other hand, upon ALA treatment cAMP level was significantly increased as compared to diabetic group thus rescued defects in cAMP signalling which is antiapoptotic in $\beta$-cells as formerly explained. To the best of our knowledge no studies were done to evaluate the antiapoptotic effect of ALA mediated through its effect on cAMP level in pancreatic tissue in T2DM. Nevertheless, many in vivo and in vitro studies revealed that ALA influence cAMP level in other tissues such as the study of Banday and Fazili in 2007 [40] who reported that treatment of obese insulin resistant rats with ALA caused increase in cAMP level in the renal proximal tubular membranes via affecting the Dopamine Receptor 1 (DR-1), which is a G protein coupled receptor, where ALA rescued the DR-1 affinity and normalized the ability of the SKF-38393 (a DR-1 agonist) to induce G-protein coupling in the receptor and adenylyl cyclase activation subsequently increased cAMP accummulation in that tissue.

TXNIP acts as an endogenous inhibitor of TRX which resides mainly in the nucleus during basal conditions. However it shuttles during cellular stress such as oxidative stress to cytoplasm as well as mitochondria where it binds TRX1 \& TRX2 respectively, dislocating ASK1 from its binding to TRX allowing for ASK1 phosphorylation/ activation, resulting in induction of the ASK 1-dependant apoptotic pathway [41]. Previous studies revealed TXNIP as a proapoptotic factor favoring, when over expressed, the death of pancreatic beta cells [42]. In the current study, the protein level of TXNIP in pancreatic tissue of diabetic group was shown to be significantly increased as compared to the normal control group. This finding may possibly be the result of increased TXNIP expression as a consequence of hyperglycemia \&/or increased translocation from the nucleus due to oxidative stress which is consistent with results of Minn and Hafele in 2005 [10] who reported that glucose induced $\beta$-cell TXNIP transcription through a distinct carbohydrate response element (ChoRE) which induced pancreatic $\beta$-cells apoptosis. Saxena and chen in 2010 reported that oxidative stress of pancreatic beta cells induced translocation of TXNIP from nucleus to mitochondria \& induced beta cell apoptosis via ASK1 signaling pathway
[43]. Furthermore, the present study revealed a significant decrease in TXNIP protein level in pancreatic tissue of ALA-treated group when compared to diabetic group thus providing an experimental evidence for a possible protective role of ALA against $\beta$-cell apoptosis in T2DM. Given that high glucose has been reported to induce TXNIP gene expression in pancreatic $\beta$-cells [44], it is tempting to hypothesize that the reported decrease of TXNIP protein level in the ALA-treated group is due to the ameliorative effect of ALA on blood glucose level in the same group. Also cAMP has been reported to increase the proteasome mediated degradation of TXNIP in pancreatic $\beta$-cells $[45,46]$, therefore the reported increase of cAMP level in ALA-treated group may be also another mechanism for the decreased TXNIP level by ALA treatment.

\section{Conclusion:}

The current study provided an evidence that oxidative stress and disturbed cAMP signaling along with increased TXNIP level in pancreatic tissue acted as major contributing factors for pathogenesis of high fat diet-induced T2DM. It also proved that ALA has a potential therapeutic value in T2DM which is possibly accredited to its antioxidant and hypoglycemic effects. Moreover, ALA was found to have an ameliorative effect on pancreatic apoptosis as demonstrated by the upregulated cAMP protein level and downregulated TXNIP protein level. Thus, ALA could possibly serve not only as a therapeutic but also as a preventive agent modulating the course of the pathogenesis of T2DM.

\section{References}

1- ZHENG Y., LEY S.H. and HU F.B.: Global aetiology and epidemiology of type 2 diabetes mellitus and its complications. Nature Reviews Endocrinology, 14 (2): 88, 2018.

2- VAN RAALTE D.H. and VERCHERE C.B.: Improving glycaemic control in type 2 diabetes: $\mathrm{S}$ timulate insulin secretion or provide beta-cell rest? Diabetes, Obesity and Metabolism, 19 (9): 1205-13, 2017.

3- MOURAD A.A., HEEBA G.H., TAYE A. and ELMOSELHY M.A.: Comparative study between atorvastatin and losartan on high fat diet-induced type 2 diabetes mellitus in rats. Fundam. Clin. Pharmacol., 27 (5): 489 97, 2013.

4- SREEDHAR R., ARUMUGAM S., THANDAVARAYAN R.A., KARUPPAGOUNDER V., KOGA Y., NAKAMURA T., HARIMA M. and WATANABE K.: Role of 14$3-3 \eta$ protein on cardiac fatty acid metabolism and macrophage polarization after high fat diet induced type 2 diabetes mellitus. The International Journal of Biochemistry \& Cell Biology, 88: 92-9, 2017.

5- JEZEK P., JABUREK M. and PLECITA-HLAVATA L.: Contribution of oxidative stress and impaired biogenesis 
of pancreatic $\beta$-cells to type 2 diabetes. Antioxidants and Redox Signaling. Doi: 10.1089/ars.2018.7656, 2018.

6- TSIKAS D.: Assessment of lipid peroxidation by measuring Malondialdehyde (MDA) and relatives in biological samples: Analytical and biological challenges. Analytical biochemistry, 524: 13-30, 2017.

7- HUANG C.J., HAATAJA L., GALASSO R., GURLO T., BUTLER A.E., SOELLER W. and BUTLER P.C.: Induction of endoplasmic reticulum stress induced beta cell apoptosis and accumulation of polyubiquitinated proteins by human islet amyloid polypeptide. American Journal of Physiology-Endocrinology and Metabolism, 293 (6): E1656-E1662, 2017.

8- INSEL P.A., ZHANG L., MURRAY F., YOKOUCHI H. and ZAMBON A.C.: Cyclic AMP is both a pro-apoptotic and anti-apoptotic second messenger. Acta Physiol., 204 (2): 277-87, 2012.

9- NASOOHI S., ISMAEL S. and ISHRAT T.: ThioredoxinInteracting Protein (TXNIP) in Cerebrovascular and Neurodegenerative Diseases: Regulation and Implication. Mol. Neurobiol., 55 (10): 7900-7920, 2018.

10- MINN A.H., HAFELE C. and SHALEV A.: Thioredoxininteracting protein is stimulated by glucose through a carbohydrate response element and induces $\beta$-cell apoptosis. Endocrinology, 146 (5): 2397-405, 2005.

11- CHEN J., HUI S.T., COUTO F.M., MUNGRUE I.N., DAVIS D.B., ATTIE A.D., et al.: Thioredoxin-interacting protein deficiency induces Akt/Bcl-xL signaling and pancreatic beta-cell mass and protects against diabetes, 3581-94, 2008.

12- KUCUKGONCU S., ZHOU E., LUCAS K.B. and TEK C.: Alpha-Lipoic Acid (ALA) as a supplementation for weight loss: Results from a meta-analysis of randomized controlled trials. Obes. Rev., 18 (5): 594-601, 2017.

13- WEI W., WANG H., WU Y., DING K., LI T., CONG Z., et al.: Alpha lipoic acid inhibits neural apoptosis via a mitochondrial pathway in rats following traumatic brain injury. Neurochem. Int., 87: 85-91, 2015.

14- EL-MOSELHY M.A., TAYE A., SHARKAWI S. S., ELSISI S.F.I. and AHMED A.F.: The antihyperglycemic effect of curcumin in high fat diet fed rats. Role of TNF$\alpha$ and free fatty acids. Food Chem. Toxicol., 49 (5): 112940, 2011.

15- CAMERON N.E., COTTER M.A., HORROBIN D.H. and TRITSCHLER H.J.: Effects of $\alpha$-lipoic acid on neurovascular function in diabetic rats: Interaction with essential fatty acids. Diabetologia, 1; 41 (4): 390-9, 1998.

16- OHKAWA H., OHISHI N. and YAGI K.: Assay for lipid peroxides in animal tissues by thiobarbituric acid reaction. Anal. Biochem., 95 (2): 351-8, 1979.

17- AEBI H.: Catalase in vitro Methods. Enzymol., 105: 1216, 1984.

18- NISHIKIMI M., RAO N.A. and YAGI K.: The occurrence of superoxide anion in the reaction of reduced phenazine methosulfate and molecular oxygen. Biochem. Biophys. Res. Commun., 46 (2): 849-54, 1972.

19- PARSANATHAN R. and JAIN S.K.: Glutathione Deficiency Induces Epigenetic Alterations of Vitamin D Metabolism Genes in the Liver of High-Fat Diet-Induced Type 2 Diabetic Mice, 67: 1878-80, 2018.
20- MANNA P. and JAIN S.K.: Obesity, oxidative stress, adipose tissue dysfunction, and the associated health risks: Causes and therapeutic strategies. Metabolic Syndrome and Related Disorders, Dec. 1, 13 (10): 423-44, 2015.

21- LITWAK S.A., WALI J.A., PAPPAS E.G., SAADI H., STANLEY W.J., VARANASI L.C., KAY T.W., THOMAS H.E. and GURZOV E.N.: Lipotoxic stress induces pancreatic $\beta$-cell apoptosis through modulation of Bcl-2 proteins by the ubiquitin-proteasome system. Journal of Diabetes Research, 2015: 280615-31, 2015.

22- YU S., CHEN S.T., LI W., DUBEY N.K., CHEN W., CHUU J., et al.: Hypoglycemic Activity through a Novel Combination of Fruiting Body and Mycelia of Cordyceps militaris in High-Fat Diet-Induced Type 2 Diabetes Mellitus Mice. Journal of Diabetes Research, 2015: 723190$200,2015$.

23- SHOHAT N., TARABICHI M., TISCHLER E.H., JABBOUR S. and PARVIZI J.: Serum Fructosamine: A Simple and Inexpensive Test for Assessing Preoperative Glycemic Control. J.B.J.S., 99 (22): 1900-7, 2017.

24- ZONOOZI S., BARNARD M., PRESCOTT E., JONES R., SHAH F.T. and TZOULIS P.: Effectiveness and safety of sitagliptin in patients with beta-thalassaemia major and diabetes mellitus: A case series. Mediterranean Journal of Hematology and Infectious Diseases, 9 (1): e2017004, 2017.

25- NAMAZI N., LARIJANI B. and AZADBAKHT L.: Alphalipoic acid supplement in obesity treatment: A systematic review and meta-analysis of clinical trials. Clinical $\mathrm{Nu}-$ trition. Elsevier, 37 (2): 419-28, 2017.

26- EMELIANOV V.V., LEONTEV D.V., ISHCHENKO A.V., BULAVINTSEVA T.S., SAVATEEVA E.A. and DANILOVA I.G.: Atomic-force microscopy of erythrocytes and metabolic disorders in experimental diabetes mellitus and during the correction of diabetes with lipoic acid. Biophysics, 61 (6): 906-10, 2016.

27- SPIRLANDELI A.L., DEMINICE R., JORDAO A.A. and PRETO R.: Plasma Malondialdehyde as Biomarker of Lipid Peroxidation: Effects of Acute Exercise. International Journal of Sports Medicine, 35 (01): 14-8, 2014.

28- CHAN J.Y., MESSINA A., MONDA V., VALENZANO A., CINCIONE R.I., MESSINA G., et al.: Long Feeding High-Fat Diet Induces Hypothalamic Oxidative Stress and Inflammation, and Prolonged Hypothalamic AMPK Activation in Rat Animal Model, 9: 1-12, 2018.

29- FENG B., YAN X.F., XUE J.L., XU L. and WANG H.: The protective effects of $\alpha$-lipoic acid on kidneys in type 2 diabetic Goto-Kakisaki rats via reducing oxidative stress. Int. J. Mol. Sci., 14 (4): 6746-56, 2013.

30- RAHAL A., KUMAR A., SINGH V., YADAV B., TIWARI R., CHAKRABORTY S., et al.: Oxidative Stress, Prooxidants, and Antioxidants: The Interplay. Biomed research international, 2014: 761264-83, 2014.

31- ANWER T., SHARMA M., PILLAI K.K. and KHAN G.: Protective effect of withania somnifera against oxidative stress and pancreatic $\beta$-cell damage in type 2 diabetic rats. Acta Pol. Pharm., 69 (6): 1095-101, 2012.

32- UCHENDU C.: Chronic co-exposure to chlorpyrifos and deltamethrin pesticides induces alterations in serum lipids and oxidative stress in Wistar rats: Mitigating role of 
alpha-lipoic acid. Environmental Science and Pollution Research, 19605-11, 2018.

33- YANG H. and YANG L.: Targeting cAMP/PKA Pathway for Glycemic Control and Type 2 Diabetes Therapy. Journal of Molecular Endocrinology, 57 (2): R93-R108, 2016.

34- PORTHA B. and MOVASSAT J.: Activation of the GLP1 Receptor Signalling Pathway: A Relevant Strategy to Repair a Deficient Beta-Cell Mass. Exp. Diabetes Res., 2011: 376509-20, 2011.

35- HUI H., NOURPARVAR A., ZHAO X. and PERFETTI R.: Glucagon-like peptide-1 inhibits apoptosis of insulinsecreting cells via a cyclic 5'-adenosine monophosphatedependent protein kinase A-and a phosphatidylinositol 3-kinase-dependent pathway. Endocrinology, 144 (4): 1444-55, 2003.

36- KIM S.J., NIAN C., WIDENMAIER S. and McINTOSH C.H.: Glucose-dependent insulinotropic polypeptidemediated up-regulation of $\beta$-cell antiapoptotic Bcl-2 gene expression is coordinated by cyclic AMP (cAMP) response element binding protein (CREB) and cAMP-responsive CREB coactivator 2. Molecular and cellular biology, 28 (5): 1644-56, 2008.

37- STEWART A.F., HUSSAIN M.A., GARCÍA-OCAÑA A., VASAVADA R.C., BHUSHAN A. and BERNALMIZRACHI E.: Human $\beta$-cell Proliferation and Intracellular Signaling: Part 3. Diabetes, 64 (6): 1872-85, 2015.

38- WELTERS H.J., DIAKOGIANNAKI E., MORDUE J.M., TADAYYON M., SMITH S.A. and MORGAN N.G.: Differential protective effects of palmitoleic acid and cAMP on caspase activation and cell viability in pancreatic $\beta$-cells exposed to palmitate. Apoptosis, 11 (7): 1231-8, 2006.

39- TIAN G., SOL E.R., XU Y., SHUAI H. and TENGHOLM A.: Impaired cAMP generation contributes to defective glucose-stimulated insulin secretion after long-term exposure to palmitate. Diabetes, 1; 64 (3): 904-15, 2015.

40- BANDAY A.A., FAZILI F.R., MARWAHA A. and LOKHANDWALA M.F.: Mitogen-activated protein kinase upregulation reduces renal D1 receptor affinity and Gprotein coupling in obese rats. Kidney Int., 71 (5): 397 406, 2007.

41- LANE T., FLAM B., LOCKEY R. and KOLLIPUTI N.: TXNIP shuttling: Missing link between oxidative stress and inflammasome activation. Frontiers in physiology, 4: 50. Doi: 10.3389/fphys.2013.00050, 2013.

42- MASSON E., KOREN S., RAZIK F., GOLDBERG H., KWAN E.P., SHEU L., et al.: High $\beta$-cell mass prevents streptozotocin-induced diabetes in thioredoxin-interacting protein-deficient mice. Am. J. Physiol. Metab., 296 (6): E1251-61, 2009.

43- SAXENA G., CHEN J. and SHALEV A.: Intracellular shuttling and mitochondrial function of thioredoxininteracting protein. Journal of Biological Chemistry, 285 (6): 3997-4005, 2010.

44- CHA-MOLSTAD H., SAXENA G., CHEN J. and SHALEV A.: Glucose-stimulated expression of Txnip is mediated by carbohydrate response element-binding protein, p300, and histone $\mathrm{H} 4$ acetylation in pancreatic beta cells. Journal of Biological Chemistry, 284 (25): 16898-905, 2009.

45- SHAO W., YU Z., FANTUS I.G. and JIN T.: Cyclic AMP signaling stimulates proteasome degradation of thioredoxin interacting protein (TxNIP) in pancreatic $\beta$-cells. Cell Signal., 22 (8): 1240-6, 2010.

46- HAO CYLYN and ZHANG FYYL: Geniposide accelerates proteasome degradation of Txnip to inhibit insulin secretion in pancreatic $\beta$-cells. J. Endocrinol. Invest., 40 (5): 505-12, 2017. 


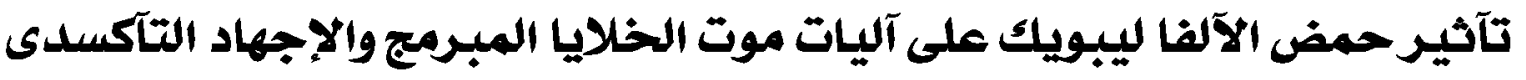

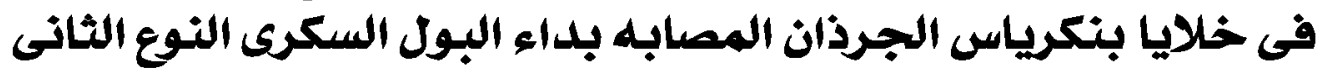

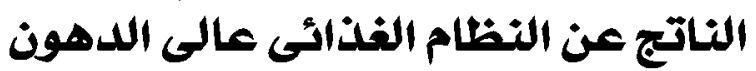

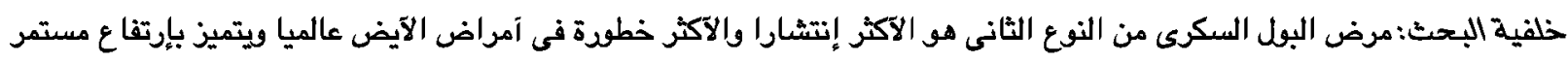

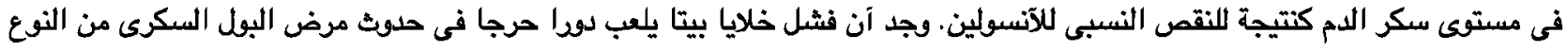

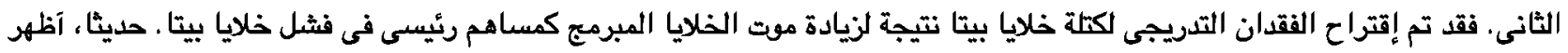

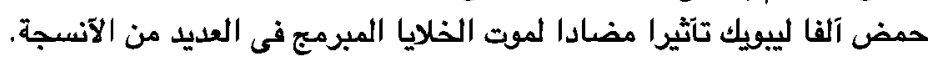

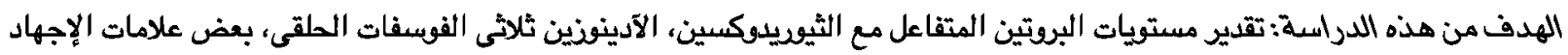

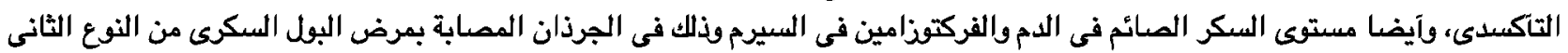

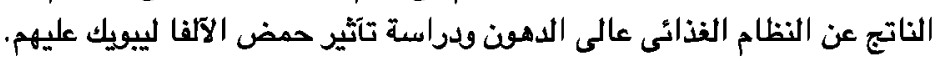

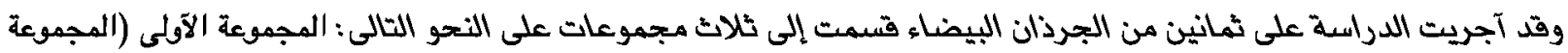

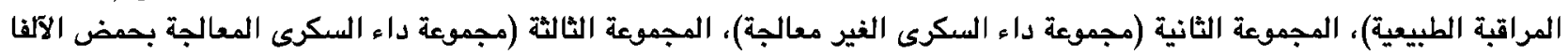

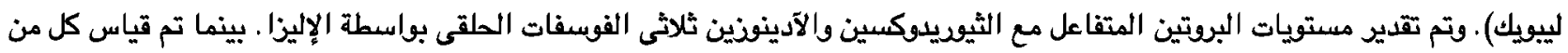

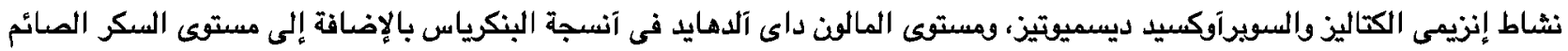
فى الدم والفركتوزامين فى البلازما بواسطة التحليل الطيفى.

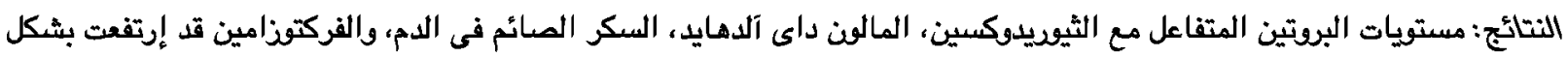

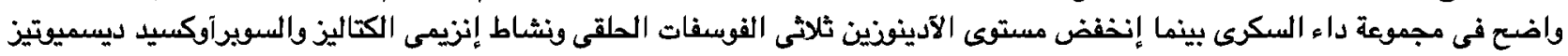

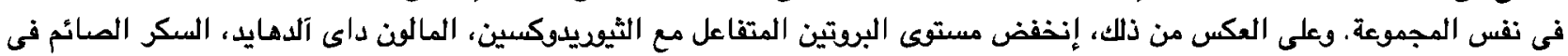

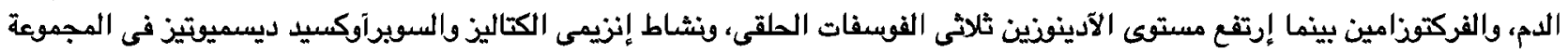
المعالجة بحمض الآلفا ليبويك.

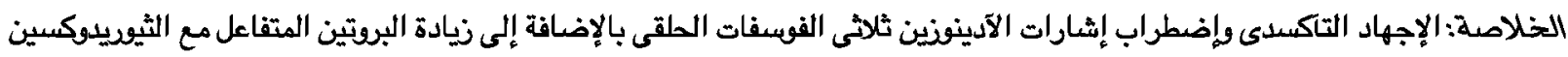

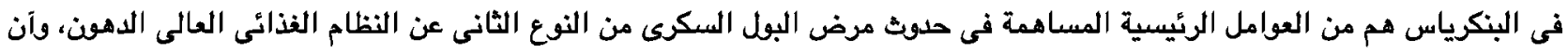

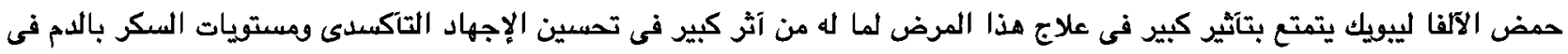

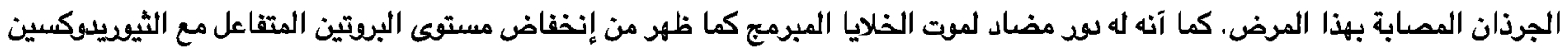

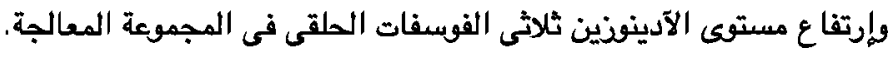

